\title{
Are Maternity Experiences of Rural Women Getting Better with Time? Results from a Survey in Tasmania
}

\author{
Ha Hoang*, Quynh Lê, Daniel Terry \\ Department of Rural Health, University of Tasmania, Locked Bag 1372, Launceston, Tasmania 7250, Australia \\ *Corresponding Author: Thi.Hoang@utas.edu.au
}

Copyright (C) 2013 Horizon Research Publishing All rights reserved.

\begin{abstract}
This study investigates the maternity experiences of rural women in Tasmania; and whether the childbirth experiences between women who have had childbirth experiences within the last five years and those more than five years ago are different due to closure of local maternity services. A questionnaire explored women's experiences of rural maternity services from antenatal to postnatal care in six rural communities in Tasmania, Australia. 210 women completed the questionnaire with a response rate of $35 \%$. Nearly $50 \%(n=100)$ of surveyed women did not have a choice where they could get antenatal care, while more than $50 \%(n=108)$ of participants lacked the choice about who would provide care during their pregnancy. Women who gave birth recently were more likely to have to travel further to the nearest maternity units. These women were less likely to experience continuity of care and to be satisfied with the antenatal care and care during labour. In contrast, the women who gave birth more than five years ago had shorter travel time to the nearest maternity units and were more likely to have experienced continuity of care and greater satisfaction with care given during their pregnancy, labour and delivery. Maternity experiences of Tasmanian rural women have not improved with time due to the closure of small rural maternity units. Reopening small rural maternity units would not be feasible with the current shortage of health workforce in Australia. However, in order to improve maternity experiences for rural women, it is recommended that basic services including antenatal and postnatal services should be provided in their local communities. The existing maternity health providers in rural communities such as GP obstetricians and multi-skilled rural nurses should be encouraged and provided with incentives to deliver greater antenatal and postnatal care for women. In addition, maternity health providers from major hospitals could come to a local hospital regularly to provide antenatal check-ups and antenatal classes. This will reduce the need of traveling to access services and increase opportunities for continuity of care which in turn may increase the satisfaction with care of rural women.
\end{abstract}

Keywords Rural Maternity Services, Closure, Rural
Women, Tasmania, Australia

\section{Introduction}

In Australian rural and remote areas, communities have experienced on going loss of maternity services with more than $50 \%$ of small rural maternity units being closed since 1995 [1]. There are three principle, yet interrelated reasons which have led to the loss of maternity services in rural communities. These include the shortage of health workforce [2,3], safety and quality concerns [1] and cost considerations $[1,4]$. However, research suggested that closures shift costs and risk from the health care system to rural families [5] in the form of transport, child care cost and risk of having labour on route to the hospital. Klein et al. [4] emphasise, "cost savings may prove elusive because the decision to close hospitals in smaller communities carries with it health and economic risks".

Despite concerns on the safety of small rural maternity units, there has been emerging and on-going evidence supporting the safety of small rural maternity units. For example, a Canadian study [6] showed improved outcomes when providing a midwifery-led collaborative model of care in remote communities. An American study [7] demonstrated that the outcomes of infants born to women from communities even with the poorest local access were more favourable than those born to women who delivered out of their local communities at larger maternity units. In addition, an Australian study [8] found that the likelihood of neonatal death was significantly less in smaller maternity hospitals.

Although the lack of rural maternity services and its impact on the health outcomes of women and babies has been widely researched, studies concerning the maternity experiences of rural women and how these experiences differ according to the length of time since child birth experience are limited. As such, this study investigates the maternity experiences of Tasmanian rural women and whether the 
experiences between women who have had childbirth experiences recently and those who gave birth some years ago are different due to closure of local maternity services. The results of this study will inform policy makers and the State Government about the service designs and provision of maternity services in rural Tasmania.

\section{Methods}

This study was part of a wider research project identifying women's needs in rural areas of Tasmania, Australia, employing mixed methods approach [9].

\subsection{Research Questions}

The research questions pertaining to this section of the study included:

- What are maternity care experiences of rural women from antenatal to postnatal care?

- How does this differ from women who have had childbirth experience recently to those who gave birth some years ago?

Data collection methods included a survey and semi-structured interviews. Ethics approval for the study was granted by the Tasmanian Social Sciences Human Research Ethics Network. This paper reports the results of the survey.

\subsection{Survey}

The survey consists of 41 questions which were informed by the literature and was divided into four parts: Part A about respondent's demographic background; Part B about their most recent experiences of maternity services; Part $\mathrm{C}$ about the participant's views on maternity services in rural areas; and Part D about optional comments of participants. The questionnaire included fifteen questions using a 5-point Likert scale ranging from "Strongly Agree" to "Strongly Disagree". Prior the questionnaire's full implementation, a pilot study was conducted with 20 participants. The reliability of the fifteen Likert scale questions were tested using Cronbach's alpha with a result of $\alpha=0.746(\alpha>0.7)$ which is considered acceptable [10]. In addition a number of useful suggestions were received from the pilot study participants and incorporated in the survey.

Participants were recruited through the health care centres in six rural communities in Tasmania. The health centres in these communities currently provide very limited maternity care services and are 45-120 min from a major hospital by car. Third parties such as health and child care centres in these communities were approached for participant recruitment. The selection criteria for participants were:

- being a female over 18 years of age;

- having had childbirth experiences; and

- living in rural areas of Tasmania at the time of giving birth.

Between May and Sep 2010, six hundred surveys were distributed to women who met the study criteria. When the survey was closed, 210 questionnaires were returned $(35 \%$ response rate).

\subsection{Analysis}

Data from the questionnaires were coded and entered into SPSS version 15.0 [11]. Descriptive statistics and Chi Square tests were used to analyse the data. Results were considered statistically significant at $\mathrm{p}<=0.05$.

\section{Results}

The survey participants were asked about their maternity care experiences including antenatal care, childbirth care and postnatal care. The characteristics of the survey participants are presented in Table 1. In addition the responses were analysed and coded by themes.

Table 1. Characteristics of survey respondents

\begin{tabular}{|c|c|c|}
\hline Characteristics & $\begin{array}{c}\text { Number of } \\
\text { participants } \\
(\mathrm{N})\end{array}$ & $\begin{array}{l}\text { Percentage } \\
\quad(\%)\end{array}$ \\
\hline \multicolumn{3}{|l|}{ Age group } \\
\hline 18-21 years & 2 & 1.0 \\
\hline 22-30 years & 42 & 20.1 \\
\hline $31-40$ years & 77 & 36.8 \\
\hline Over 40 years & 88 & 42.1 \\
\hline \multicolumn{3}{|l|}{ Education } \\
\hline Primary school & 2 & 1.0 \\
\hline Secondary school & 111 & 53.1 \\
\hline University & 67 & 32.1 \\
\hline Other & 29 & 13.9 \\
\hline \multicolumn{3}{|l|}{ Language spoken at home } \\
\hline English & 203 & 97.1 \\
\hline Other & 6 & 2.9 \\
\hline \multicolumn{3}{|l|}{$\begin{array}{c}\text { An Aboriginal or Torres Strait } \\
\text { Islander }\end{array}$} \\
\hline No & 201 & 96.2 \\
\hline Yes & 8 & 3.8 \\
\hline \multicolumn{3}{|l|}{ Most recent baby } \\
\hline Less than a year ago & 33 & 15.9 \\
\hline 1 to 2 years ago & 33 & 15.9 \\
\hline Over 2 to 5 years ago & 51 & 24.5 \\
\hline Over 5 years ago & 91 & 43.8 \\
\hline \multicolumn{3}{|l|}{ Type of delivery } \\
\hline Vaginal delivery & 128 & 62.4 \\
\hline Caesarean delivery & 47 & 22.9 \\
\hline Induced labour & 21 & 10.2 \\
\hline Mixed type of delivery & 9 & 4.4 \\
\hline \multicolumn{3}{|l|}{$\begin{array}{c}\text { Travel time to the nearest maternity } \\
\text { unit }\end{array}$} \\
\hline Less than an hour's drive & 122 & 58.4 \\
\hline One to two hours' drive & 77 & 36.8 \\
\hline More than two hours' drive & 9 & 4.3 \\
\hline
\end{tabular}




\subsection{Antenatal Care}

\subsubsection{Choice}

Nearly $50 \%(n=95)$ of surveyed women reported that they did not have any options in places where they could get antenatal care. Furthermore, the survey results revealed that more than $50 \%(n=103)$ of participants were not given an option about who would provide care during their pregnancy. The statistical analysis demonstrates that there is a relationship between "level of education" and the "women's choice regarding whom women could see for antenatal check-ups" (Chi-Square Value $(\chi 2)=7.09, \mathrm{df}=1, \mathrm{p}$-value $=$ $0.0077<0.05)$. In particular, those women who have had tertiary education $(n=92,46 \%)$ are more likely to say that they had a choice of health professionals $(n=54,27 \%)$. The participants who completed up to secondary school $(n=108$, $54 \%$ ) tend to claim that they had no option given to them regarding whom they could see for antenatal check-ups $(n=65,32.5 \%)$.

\subsubsection{Attendance to Antenatal Care}

$96.1 \% \quad(n=202)$ of surveyed women reported to have attended antennal check-ups. As shown in Figure 1, the women went to many different places for their check-ups. The Chi Square test results show that driving time from the women's normal residence to the nearest maternity unit at the time they had their babies has an effect on the place where women get their antenatal check-ups (Chi-Square $\left(\chi^{2}\right)$ $=32.99, \mathrm{df}=4, \mathrm{p}$-value $=0.00<0.05)$. This explains that distance to the major hospital is an important influencing factor for women when deciding to access certain services available to them.

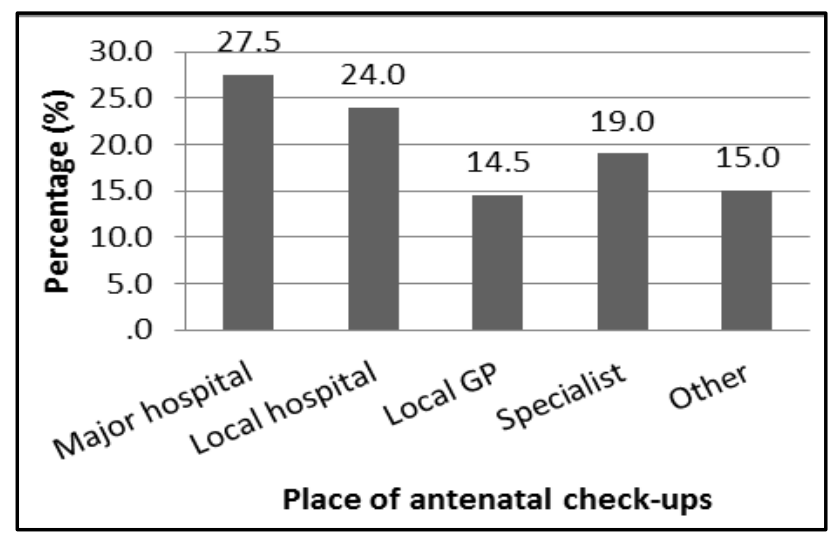

Figure 1. Place of antenatal check-ups

More than half $(n=106,51.2 \%)$ of the respondents attended antenatal education and $48.8 \%(n=104)$ stated that they did not participate in antenatal classes. Figure 2 indicates that over $50 \%$ attended antenatal classes in major hospitals.

\subsubsection{Care Rating}

The participants were asked to rate their satisfaction of the care and services provided to them. This is shown in
Figure 3.

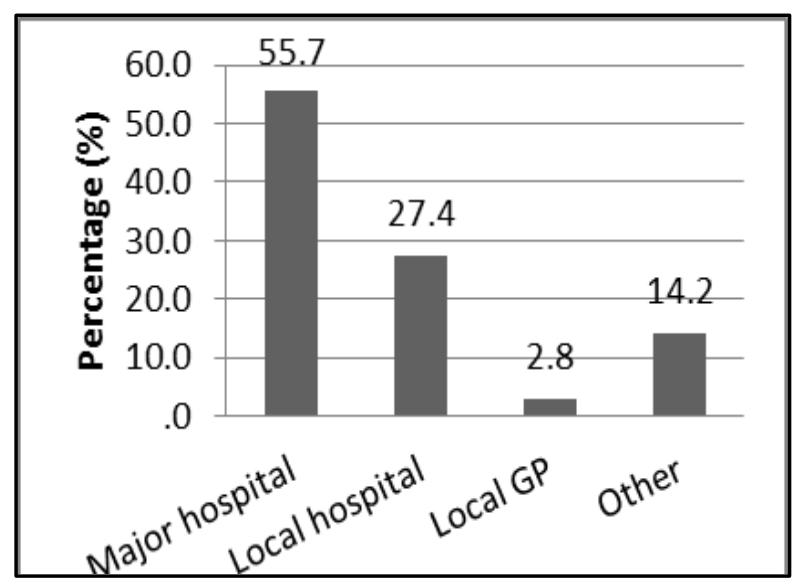

Figure 2. Place of antenatal classes

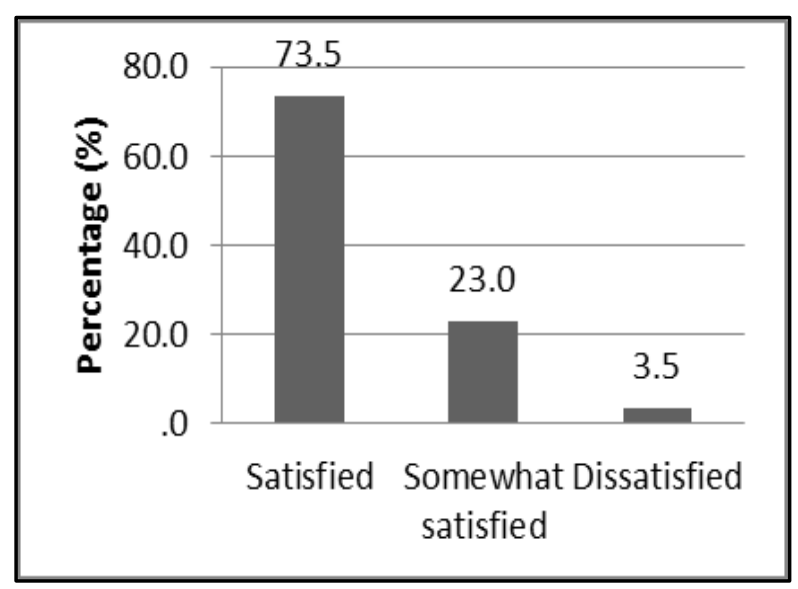

Figure 3. Rating of antenatal care

For those participants who attended antenatal education, they were asked to evaluate the services in two aspects. First, how well they thought the antenatal classes had prepared for their childbirth and second, how well the antenatal classes had prepared them for looking after their babies. Figures 4 and 5 show that in both cases more than $50 \%$ rated the services as "reasonably well".

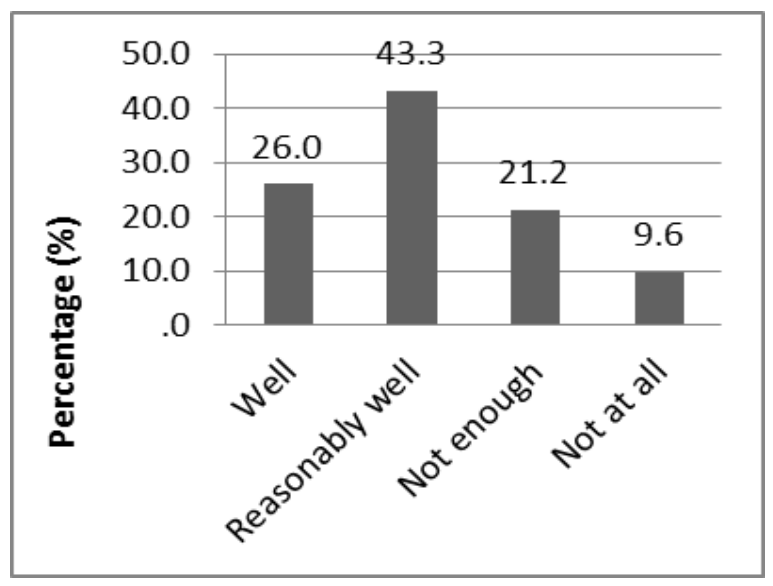

Figure 4. Rating of antenatal classes 


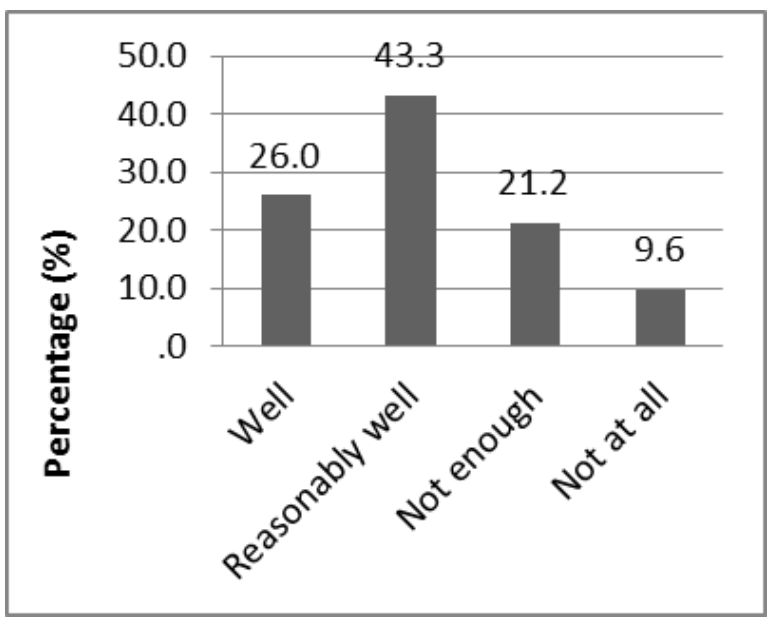

Figure 5. How well antenatal classes prepared to look after a baby

\subsection{Labour and Delivery Care}

\subsubsection{Choice of Place and Actual Place for Baby Delivery}

Similar to antenatal care, $58 \%$ of the participants said they did not have a choice where to give birth with nearly $60 \%$ having their babies in a major hospital as shown in Figure 6.

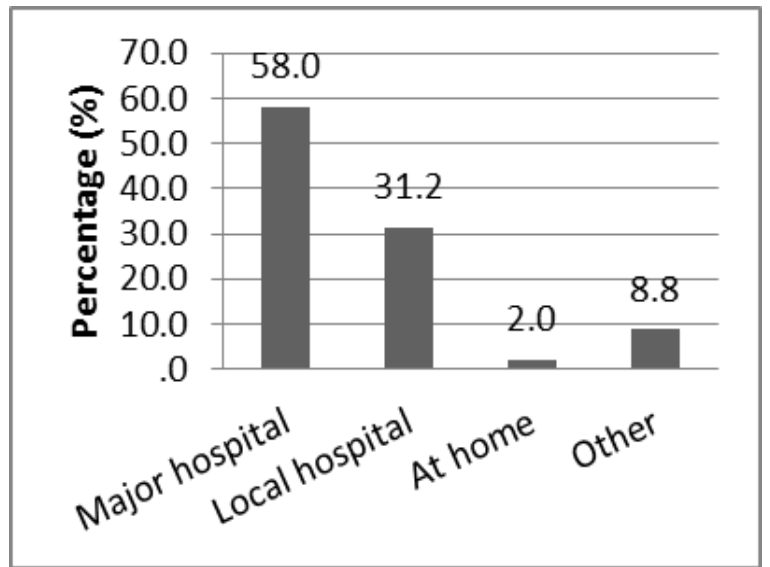

Figure 6. Place of giving birth

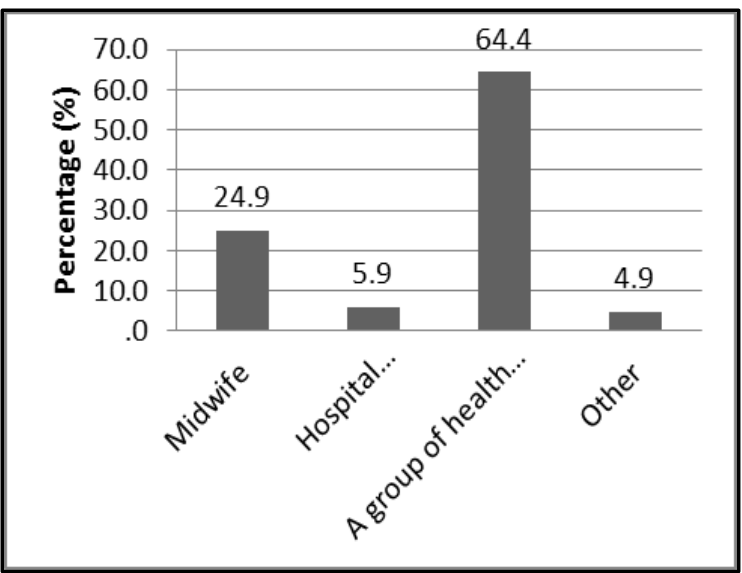

Figure 7. Health professionals' presence during labour/childbirth

\subsubsection{Type of Health Professionals}

The participants were asked what health professionals provided care and support to them during labour and delivery. As shown in Figure 7, over 60\% received care during labour and delivery from a group of health professionals including doctors, midwives and nurses.3.2.3. Care Rating

In regard to labour care, about $74 \%$ of the women were satisfied with the care that they received. Less than $20 \%$ said they were somewhat satisfied. These results are illustrated in Figure 8.

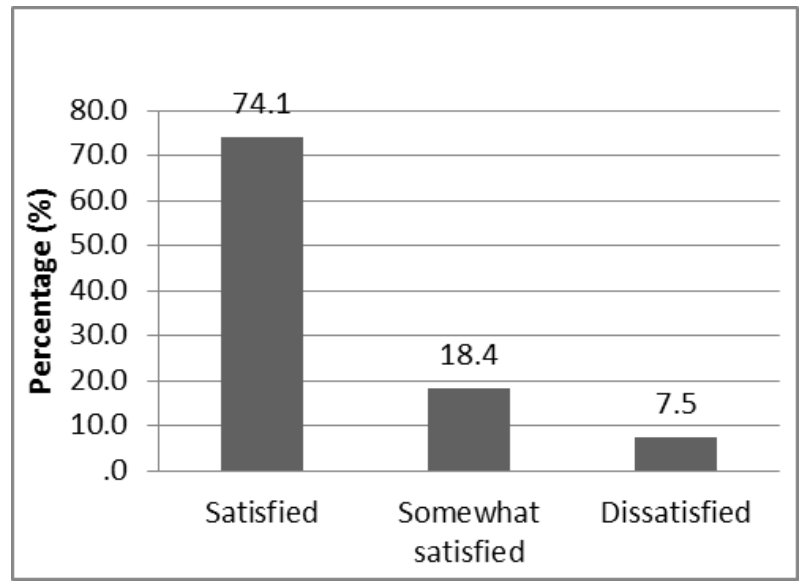

Figure 8. Rating of labour/childbirth care

\subsection{Postnatal Care}

The results from the survey indicate that local GPs were the main health professionals who performed postnatal check for the women in the study $(\mathrm{n}=97,46.4 \%)$. This is illustrated in Figure 9.

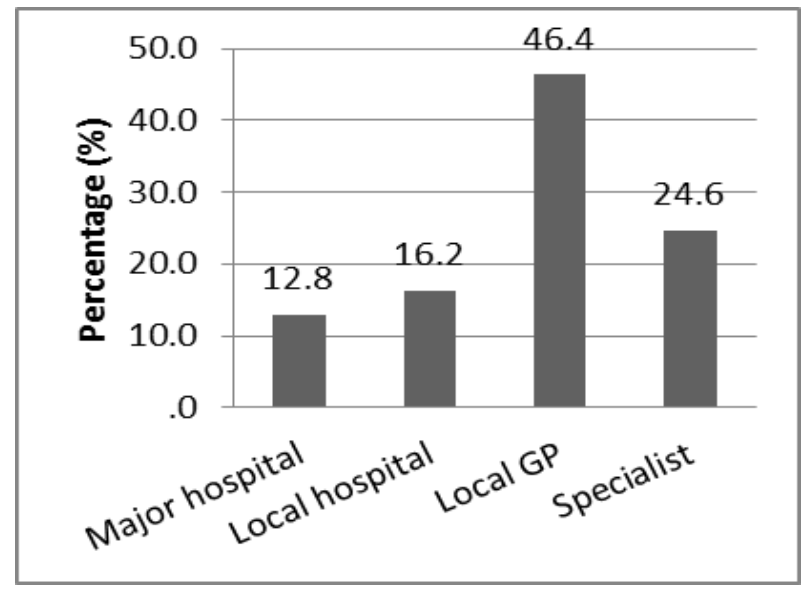

Figure 9. Postnatal care providers

More than $90 \%$ of the participants brought their babies to check-ups, with child health centres being the principle place where babies had check-ups $(n=134,64 \%)$ as shown in Figure 10.

The majority $(\mathrm{n}=160,76.1 \%)$ of the participants were 
satisfied with the postnatal care that they received as illustrated in Figure 11.

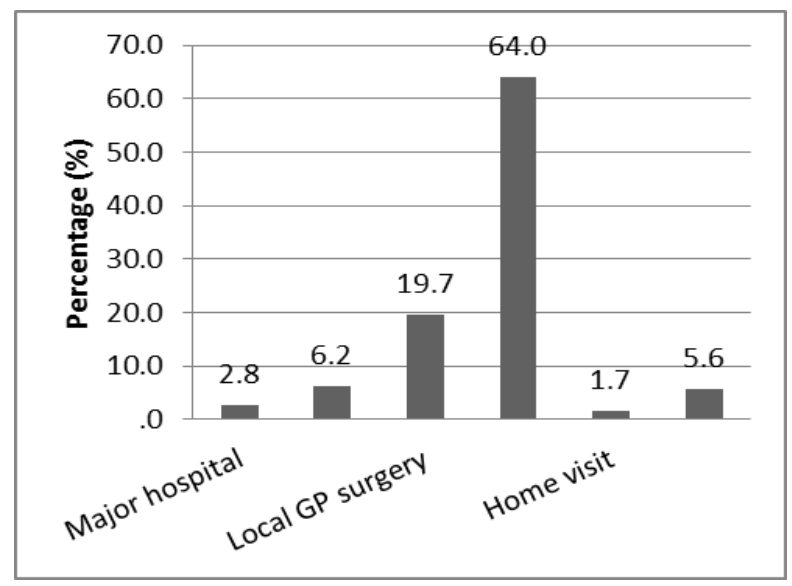

Figure 10. Care providers of baby check-ups

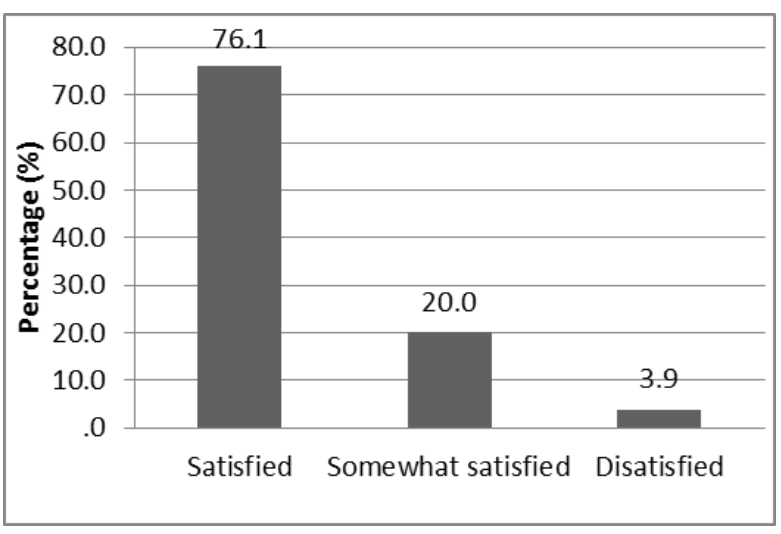

Figure 11. Rating of postnatal care

\subsection{Differences in Maternity Experiences by the Length of Time Since Their Last Child Birth Experiences}

The study found that the women's length of time since last childbirth experience significantly impacted their experience in maternity care.

\subsection{The Nearest Maternity Unit}

Statistical results show that there is a relationship between the respondent's length of time since last childbirth experience and the drive time from her residence to the nearest maternity unit (Chi-Square Value $\left(\chi^{2}\right)=47.57, \mathrm{df}=$ 1 , p-value $=0.00<0.05)$. Particularly, those women who gave birth in the last five years $(\mathrm{n}=118,56.5 \%)$ were more likely to travel for more than 1 hour $(\mathrm{n}=80,38.3 \%)$ to the nearest maternity units. The women whose childbirth experience had been more than five years ago $(n=91,43.5 \%)$ were less likely to travel that far $(n=18,8.6 \%)$. These results reflect the fact that small local maternity units across Australia have been closed in the last two decades and consequently rural women have to travel a long way to access obstetric care which is no longer available in their local communities.

\subsection{Type of Caregivers During Pregnancy}

The Statistical test demonstrates that the respondent's length of time since last childbirth experience correlates with her experience with the types of health professionals providing care during her pregnancy (Chi-Square Value $(\chi 2)$ $=14.226, \mathrm{df}=3$, $\mathrm{p}$-value $=0.003<0.05)$. For instance, more of the women who gave birth in the last five years had a group of care givers $(\mathrm{n}=57,28.5 \%)$ during their pregnancy. Whereas, fewer of those who gave birth more than five years ago experienced different caregivers $(n=31,15.5 \%)$ during their pregnancy. These results again might reflect the loss of local maternity services. As a consequence, pregnant women have to travel to major hospitals to access care and thus experience different caregivers.

\subsection{Experience of Continuity of Care}

The statistical analysis suggests that there is an association between the women's length of time since last childbirth experience and their experience of continuity of care (Chi-Square Value $(\chi 2)=15.961, \mathrm{df}=1, \mathrm{p}$-value $=$ $0.000<0.05$ ). In particular, more of those women who had childbirth experience in the last five years had different health professionals each visit during their antenatal care. This happened less to those who gave birth more than five years ago. These results are consistent with the previous results regarding the types of health professionals and therefore reflect the same fact that women who gave birth more recently were given care in the bigger hospitals where they experienced different health professionals each visit.

\section{Rating of Care}

\subsubsection{Antenatal Care}

The test results indicates that length of time since last childbirth experience affects how the respondents rate the quality of antenatal care they received (Chi-Square Value $(\chi 2)=11.09, \mathrm{df}=1, \mathrm{p}$-value $=0.0009<0.05)$. Noticeably, the longer the length of time since last childbirth experience, the more they were satisfied with the antenatal care. In other words, the women who gave birth more than five years ago seemed to be more satisfied with the antenatal care than those who gave birth more recently.

\subsubsection{Antenatal Classes}

The statistics results indicates another significant difference between the two groups of women who had childbirth experience within five years and more than five years ago lies in their evaluation of the quality of antenatal classes (Chi-Square Value $\left(\chi^{2}\right)=11.88, \mathrm{df}=2, \mathrm{p}$-value $=$ $0.0026<0.05)$. Women who gave birth recently were also less likely to think that these classes had prepared them well for looking after their babies. Whereas, the other group of women were more likely to think they had been prepared well for taking care of their newborns.

\subsubsection{Labour and Delivery Care}


Lastly, it was indicated that there is a relationship between the respondents' length of time since last childbirth experience and their rating of care received during labour and delivery (Chi-Square Value $(\chi 2)=18.135$, $\mathrm{df}=2$, $\mathrm{p}$-value $=0.000<0.05)$. For instance, the women $(\mathrm{n}=112$, $55.7 \%$ ) who gave birth more recently were more likely to be dissatisfied $(\mathrm{n}=13,6.5 \%)$ and less likely to be satisfied $(\mathrm{n}=70,34.8 \%)$ with the care they received in labour. Whereas the other group $(\mathrm{n}=89,44.3 \%)$ were more likely to be satisfied $(\mathrm{n}=79,39.3 \%)$ and less likely to be dissatisfied $(\mathrm{n}=2,1 \%)$ with the care they were given during labour.

\section{Discussion}

The results of the study have suggested that maternity experiences of Tasmanian rural women may not be necessarily improved with time. For instance, the women who gave birth recently were more likely to have to travel further to the nearest maternity units. They were less likely to experience continuity of care and to be satisfied with the antenatal classes, antenatal care and care during labour and delivery. In contrast, the women who gave birth more than five years ago had shorter travel time to the nearest maternity units. These women were more likely to have experienced continuity of care and to be satisfied with care given from during their pregnancy and labour and delivery. These results may reflect the fact that many rural communities have lost their maternity services in the last decades. The unavailability of these services may explain why many women had a limited choice in places of birth and who would be providing care during their pregnancy.

Published qualitative data from this study [5] supports this finding suggesting that women who gave birth in their local hospital often recalled a good childbirth experience and concerned for other women who were no longer able to deliver in their own community. This is also supported by the Rural Doctors Association of Australia, which notes that: "Rural women have the right to choose birthing at hospitals in their own communities supported by their family and friends and continuity of care from their local maternity service. Robust evidence shows that small rural hospitals are safe places to give birth. Yet despite their proud record, more than 130 rural maternity units have been closed since 1995" [1].

Due to the closure of maternity services in rural communities, women who gave birth recently had to travel longer to access services. The literature suggested women who had to travel out of their communities incurred financial costs to meet their access needs, such as travel expenses, accommodation and food expenses and child care costs [12-14]. In addition, when women have to travel out of their community to access care, they also encounter social disruption $[5,12]$ as they have to leave their social support networks. All of these may contribute to the dissatisfaction with care that women who gave birth recently received.
One of the main findings from the study is that women who gave birth some years ago were more likely to have had continuity of care than those who gave birth more recently. Many studies found that continuity of care affects women's satisfaction with care [15-17]. This may explain why women who gave birth in small local hospitals were more likely to be satisfied with antennal and labour care experience as they had more chance to ask questions if they had any concerns and saw the health professionals more often. This might be difficult in the bigger hospitals with busy staff and contribute to the dissatisfaction with care of women who gave birth within the last five years. The study results also suggest that continuity of care may be more possible in a small local maternity unit than in a bigger hospital.

\section{Limitations}

Due to time and budget constraints, the study was conducted in only six selected rural areas. Thus, the results of the study may not be representative of the larger population of rural women in Tasmania. Nevertheless, it captured many differences in maternity experiences of women due to the closures of maternity services in the six rural communities in Tasmania.

\section{Conclusion}

The survey of 210 women in six rural communities in Tasmania has suggested that maternity experiences of Tasmanian rural women have not improved with time due to the closure of small rural maternity units. Reopening small rural maternity units would not be feasible with the current shortage of health workforce in Australia. However, in order to improve maternity experiences for rural women, it is recommended that basic services including antenatal and postnatal services should be provided in their local communities. The existing maternity health providers in rural communities such as GP obstetricians and multi-skilled rural nurses should be encouraged and provided with incentives to deliver greater antenatal and postnatal care for women. In addition, maternity health providers from major hospitals could come to a local hospital regularly to provide antenatal check-ups and antenatal classes. This will reduce the need of traveling to access services and increase opportunities for continuity of care which in turn may increase the satisfaction with care of rural women.

\section{Acknowledgements}

We would like to thank the University of Tasmania for providing funding under the Australian Postgraduate Scholarship scheme. 


\section{REFERENCES}

[1] Rural Doctors Association of Australia. Maternity services for rural Australia. 2006.

[2] NASOG. Submission to Maternity Services Review. CROWS NEST National Association of Specialist Obstetricians

[3] and Gynaecologists, 2008.

[4] Department of Health and Ageing. Improving maternity services in Australia: Report of the Maternity Services Review: Australian Government Department of Health and Ageing; 2009.

[5] Klein M, Christilaw J, Johnston S. Loss of maternity care: the cascade of unforeseen dangers. CJRM. 2002;7:120-1.

[6] Hoang H, Le Q, Terry D. Women's access needs in maternity care in rural Tasmania, Australia: A mixed methods study. Women and Birth.

[7] Van Wagner V, Epoo B, Nastapoka J, Harney E. Reclaiming Birth, Health, and Community: Midwifery in the Inuit Villages of Nunavik, Canada. The Journal of Midwifery \& Women's Health. 2007;52:384-91.

[8] Nesbitt T, Larson E, Rosenblatt R, Hart L. Access to maternity care in rural Washington: its effect on neonatal outcomes and resource use. Am J Public Health. 1997;87:85-90. Epub 1997/01/01.

[9] Tracy S, Sullivan E, Dahlen H, Black D, Wang Y, Tracy M. Does size matter? A population-based study of birth in lower volume maternity hospitals for low risk women. BJOG.

2006;113:86-96.

[10] Tashakkori A, Teddlie CE. Handbook of mixed methods in the social and behavioural science. Thousand Oak: CA: Sage; 2003.

[11] Nunnaly J. Psychometric theory. New York: McGraw-Hill; 1978.

[12] SPSS 15.0. Command Syntax Reference Chicago: SPSS Inc; 2006.

[13] Kornelsen J, Grzybowski S. Safety and community: the maternity care needs of rural parturient women. J Obstet Gynaecol Can. 2005;27:554-61. Epub 2005/08/16.

[14] Roach S, Downes S. Caring for Australia's most remote communities: obstetric services in the Indian Ocean Territories. Rural and Remote Health (Online), Available from: http://wwwrrhorgau. 2007;7.

[15] Dietsch E, Shackleton P, Davies C, Alston M, McLeod M. 'Mind you, there's no anaesthetist on the road': women's experiences of labouring en route. Rural and Remote Health $2010 ; 10$.

[16] Biro M, Waldenstrom U, Brown S, Pannifex J. Satisfaction with team midwifery care for low and high-risk women: a randomized controlled trial. Birth. 2003;30:1-9.

[17] Rowley M, Hensley M, Brinsmead M, Wlodarczyk J. Continuity of care by a midwife team versus routine care during pregnancy and birth: a randomised trial. . Med J Aust 1995; 163:289-93.

[18] Waldenström U, Brown S, McLachlan H, Forster D, Brennecke S. Does Team Midwife Care Increase Satisfaction with Antenatal, Intrapartum, and Postpartum Care? A Randomized Controlled Trial. Birth. 2000;27:156-67. 